\title{
¿Es posible una ontología procesual de las entidades bioquímicas? Consideraciones a partir del caso de los receptores celulares y la señalización celular ${ }^{*}$
}

\author{
Fiorela Alassia \\ Universidad Nacional de la Patagonia San Juan Bosco, Comodoro Rivadavia, Argentina \\ E-mail: fiorela.alassia@gmail.com
}

Recibido: 9 de abril de 2021 | Aprobado: 15 de octubre de 2021

https://doi.org/10.17533/udea.ef.345867

\begin{abstract}
Resumen: Las macromoléculas biológicas, consideradas como los ítems del dominio bioquímico, son típicamente concebidas bajo la categoría ontológica de individuos sustanciales. En este trabajo argumentaré que el marco filosófico de la ontología procesual, según el cual el mundo viviente no está poblado de individuos sino de una jerarquía dinámica de procesos, resulta más adecuado para dar cuenta de la estructura y funcionamiento de las macromoléculas. En particular, analizaré su aplicación al fenómeno de la señalización celular y a uno de sus conceptos claves, los receptores celulares. Los conocimientos actuales en bioquímica permiten concebir los receptores como entidades procesuales y dinámicas, estabilizadas relacionalmente y no separadas del fenómeno bioquímico del que forman parte.
\end{abstract}

Palabras clave: ontología, individuos, procesos, bioquímica, receptores, señalización celular

* Este artículo es parte del proyecto de investigación "Fundamentos de Química: aspectos meta-científicos y tópicos de enseñanza" (PI. UNPSJB N ${ }^{0}$ 1650), financiado por la Secretaría de Ciencia y Técnica de la Universidad Nacional de la Patagonia San Juan Bosco (UNPSJB, Argentina). El trabajo de investigación cuenta además con el apoyo de la Facultad de Ciencias Naturales y Ciencias de la Salud de la UNPSJB.

Quisiera agradecer personalmente a la Dra. Mariana Córdoba por su continuo apoyo en la escritura de este artículo. También a los evaluadores anónimos, cuyos comentarios contribuyeron enormemente a mejorar la primera versión del trabajo. A la Universidad Nacional de la Patagonia San Juan Bosco y, finalmente, al Dr. Alfio Zambon por el permanente acompañamiento.

\section{Cómo citar este artículo}

Alassia, F. (2022). ¿Es posible una ontología procesual de las entidades bioquímicas? Consideraciones a partir del caso de los receptores celulares y la señalización celular. Estudios de Filosofía, 65, 153-175. https://doi.org/10.17533/udea.ef.345867

\section{OPEN ACCESS}




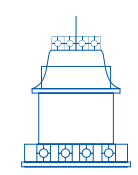

ARTÍCULOS

DE INVESTIGACIÓN

\section{Is it possible a processual ontology of biochemical entities? Considerations on the case of cell receptors and cell signaling}

Abstract: Biological macromolecules, considered as the items of the biochemical domain, are typically conceived under the ontological category of substantial individuals. In this paper, I will argue that the philosophical framework of process ontology, according to which the living world is not populated by individuals but by a dynamic hierarchy of processes, is more adequate to account for the structure and functioning of macromolecules. In particular, I will analyze its application to the phenomenon of cell signaling and to one of its key concepts, cell receptors. Current knowledge in biochemistry allows us to conceive receptors as processual and dynamic entities, relationally stabilized and not separated from the biochemical phenomenon of which they are part.

Key words: ontology, individuals, processes, biochemistry, receptors, cell signaling

Fiorela Alassia es docente investigadora en la Facultad de Ciencias Naturales y Ciencias de la Salud de la UNPSJB (Argentina). Es Bioquímica (UNPSJB), Especialista en Docencia Universitaria (UNPSJB) y Magíster en Epistemología e Historia de la Ciencia (UNTREF). Se encuentra iniciando el Doctorado en Filosofía en la Universidad de Buenos Aires. Sus áreas actuales de trabajo son la filosofía de la bioquímica y las ciencias de la salud.

ORCID: 0000-0001-6244-9629 


\section{Introducción}

Según la filósofa Johanna Seibt, desde Aristóteles en adelante, la metafísica occidental ha estado dominada por lo que la autora denomina el "paradigma o mito de la sustancia", un conjunto de presuposiciones ontológicas que se enfoca en entidades estáticas, las sustancias (principalmente concebidas bajo un dualismo de particulares y universales), como la forma más adecuada de describir la estructura del mundo (Seibt, 2018). Seibt indica que las herramientas teóricas estándar de la metafísica occidental están basadas en una visión estática de los componentes que se consideran fundamentales de la realidad. Por ejemplo, la interpretación estándar de la lógica de predicados se sustenta en términos de individuos estáticos con propiedades que se ejemplifican atemporalmente o en un determinado instante temporal (Seibt, 2021). Sin embargo, otras posiciones filosóficas sostienen que las suposiciones básicas del "paradigma de la sustancia" son prescindibles y que las entidades no tienen que ser necesariamente concebidas como individuos estáticos y, por lo tanto, pueden ser consideradas de otro modo. En particular, el marco filosófico que concibe los procesos como las entidades fundamentales del mundo contrasta con la visión sustancial y estática de la realidad. El enfoque procesual analiza prioritariamente el devenir y lo que ocurre, así como también las formas de ocurrir (Seibt, 2021).

Diferentes autores en los ámbitos de la filosofía de la química y de la biología han argumentado acerca de los beneficios de una ontología procesual para capturar el contenido inferencial de los conceptos básicos en química y en biología (Seibt, 2021). En el ámbito de la filosofía de la química podemos incluso hallar abordajes procesuales y relacionales (ver Kopel, 2019; Needham, 2003; Stein, 2004).

Más recientemente, se ha desarrollado un marco ontológico procesual en el marco de la filosofía de la biología, de acuerdo con el cual el mundo viviente no está poblado de individuos sustanciales sino fundamentalmente de procesos (Dupré \& Nicholson, 2018). Sin embargo, en el nivel bioquímico-macromolecular, este abordaje sigue siendo un desafío dado que las macromoléculas han sido típicamente estudiadas y consideradas principalmente desde el "paradigma de la sustancia", como se verá más adelante en la Sección 2.

El objetivo fundamental de este trabajo consiste en poner en consideración el marco de una ontología procesual para analizar las entidades bioquímicas. Para evaluar esto, anclaré el análisis teórico en un caso particular, el fenómeno de la señalización celular y en uno de sus conceptos claves, los receptores celulares. Estos son macromoléculas proteicas que se encuentran en las membranas celulares o en el interior celular, y que actúan como mediadores o "transmisores" de señales químicas internas o externas (por ejemplo, una hormona o un fármaco), lo que desencadena una determinada repuesta biológica (Silverman, 2004; Voet \& Voet, 2005). 
A partir de la consideración del caso de los receptores celulares, argumentaré que el marco filosófico de la ontología procesual resulta más adecuado para dar cuenta de los conocimientos actuales sobre la estructura de estas macromoléculas y su participación en el fenómeno de bioseñalización celular. Para dicho propósito, en la Sección 1 seguiré la propuesta de Lucía Lewowicz y Olimpia Lombardi (2013), de acuerdo con la cual la realidad es estructurada sobre la base de la adopción de ciertas categorías ontológicas. A partir de ello, introduciré las características principales de las categorías ontológicas de individuos sustanciales y de procesos, así como también resumiré brevemente los aspectos básicos de la concepción procesual de la ontología proveniente del marco de la filosofía de la biología. A continuación, en la Sección 2, evaluaré el modo en el cual las macromoléculas son filosóficamente concebidas en la actualidad - de acuerdo con la categoría ontológica de individuo sustancial- y presentaré resumidamente el debate reciente en filosofía de la bioquímica sobre la clasificación de proteínas y el microestructuralismo -la posición que sostiene que la función biológica está determinada por la estructura primaria de una proteína. En la Sección 3 avanzaré en la extensión de la ontología procesual aplicada a las macromoléculas biológicas, específicamente, a las proteínas. Finalmente, en la Sección 4, presentaré el caso particular de los receptores celulares y el fenómeno de señalización celular, y evaluaré si el marco de la ontología procesual no solo permite dar cuenta de forma adecuada de los conocimientos actuales sobre la temática, sino también si presenta también beneficios adicionales.

\section{Las categorías ontológicas de individuos y procesos}

Cada sector de la realidad que es estudiado por una disciplina o sub-disciplina científica, presenta una estructura que está determinada por las categorías ontológicas adoptadas o presupuestas (Lewowicz \& Lombardi, 2013). Estas categorías determinan la estructura de cada uno de los dominios científicos bajo estudio. De acuerdo con Lewowicz y Lombardi, esto significa que son las categorías ontológicas las que imponen una cierta forma (y no otra) a lo real, determinando, a su vez, los modos en que nos referimos a la realidad, es decir, los modos en los que utilizamos el lenguaje.

Si las categorías formales de un lenguaje dado pueden capturar las entidades o ítems de un determinado dominio de lo real, ello se debe a que ese lenguaje está, a su vez, organizado de acuerdo con determinadas categorías ontológicas. Es decir que las categorías ontológicas de un determinado dominio científico se "muestran" en el lenguaje. Por ejemplo, es posible distinguir entre el sujeto de predicación y las predicaciones, al asumir que la ontología está estructurada con las categorías aristotélicas de sustancia y atributos (esenciales y accidentales). Es debido al rol que cumplen las categorías ontológicas que existe un discurso significativo sobre un 
determinado dominio científico y, en consecuencia, que es posible realizar inferencias exitosas respecto de lo que ocurre en dicho dominio.

El compromiso con lo que existe en el mundo depende de las categorías ontológicas que se adopten. En este sentido, asumir, por ejemplo, que la realidad está habitada por individuos con propiedades o que únicamente existen haces de propiedades sin individuos, supone un compromiso previo con las categorías ontológicas de individuo y de propiedades. Es decir que la estructura del lenguaje nos indica qué tipo de ítems habitan la ontología asumida: si por individuos, propiedades, relaciones, procesos, etcétera. En este sentido, individuos o procesos son categorías ontológicas.

Lewowicz y Lombardi (2013) diferencian las categorías ontológicas respecto de los taxa y los conceptos de clase. Tanto desde un punto de vista lógico como desde un punto de vista ontológico, las categorías ontológicas son anteriores a cualquier clasificación, dado que una clasificación de determinados ítems presupone asumir que esos ítems existen. Las clases, por ejemplo, cumplen la función de clasificar individuos, razón por la cual utilizarlas presupone haber adoptado previamente una ontología de individuos, es decir, haber adoptado previamente la idea de que la ontología en cuestión está poblada por individuos.

Ahora bien, ¿qué son los individuos? Si bien realizar una completa caracterización metafísica de la categoría ontológica de individuo sustancial excede los objetivos de este trabajo, resulta necesario realizar algunas distinciones relevantes para dar cuenta de las siguientes secciones. Para algunos autores, los individuos existen porque hay un principio de individuación que permite distinguirlos de otros individuos ( $c f$. French \& Krause, 2006). Asimismo, otros argumentan que la individualidad consiste en dos aspectos fundamentales: la contabilidad y la identidad (cf. Kaiser \& Trappes, 2021; Krause \& Arenhardt, 2016; Lowe, 2003; 2016). Según Lewowicz y Lombardi (2013), los individuos son contables porque tienen su propia individualidad y, si son agrupados, se los puede volver a identificar dentro del grupo; en tanto que obedecen a la categoría kantiana de cantidad, cada individuo o bien es uno o bien son muchos (es decir, son una pluralidad de individuos).

Otros aspectos importantes de los individuos son sus propiedades espaciotemporales, dado que dos individuos no pueden ocupar al mismo tiempo las mismas coordenadas espaciales. Además, los individuos son indivisibles; cada individuo es una unidad completa y si sufre división, el resultado de la misma son diferentes individuos respecto del original (Lewowicz \& Lombardi, 2013).

En la filosofía occidental, los individuos son los portadores o el sustrato de las propiedades, de modo que un compromiso con la existencia de individuos implica la aceptación de una ontología de individuos y propiedades. Cuando los individuos son agrupados de acuerdo con sus propiedades (que pueden ser esenciales, responsables de la re-identificación del individuo a través del tiempo, o accidentales, es decir, cambiantes en el transcurso del tiempo), las agrupaciones 
resultantes son clases, algunas de las cuales se consideran clases naturales (Lewowicz \& Lombardi, 2013).

En el "paradigma de la sustancia" - siguiendo la expresión de Seibt-, los individuos sustanciales son entidades integradas, su existencia e identidad no dependen de relaciones externas con su entorno, que es considerado externo. La naturaleza de los individuos sustanciales está dada intrínsecamente por propiedades esenciales que, al mantenerse a través del tiempo, permiten la re-identificación del individuo. Desde esta perspectiva, el cambio es concebido como algo que les sucede a los individuos sustanciales, concebidos como los sujetos del cambio. Los procesos, entonces, involucran el "hacer" de los ítems individuales, que son preexistentes o más fundamentales. No obstante, hay procesos que no son acciones de ningún individuo u objeto individual, como el caso de la fermentación, la osmosis, la lluvia, el viento o el fuego (Dupré \& Nicholson, 2018). Esto representa un problema para el cual una ontología de individuos sustanciales no resulta satisfactoria.

El "paradigma de la sustancia" ha presentado ciertas limitaciones en el ámbito de la filosofía de la química (cf. Bensaude-Vincent, 2014; Schummer, 1998). En la discusión acerca de cuál es el estatus ontológico de las entidades químicas (Ruthenberg \& van Brakel, 2008), se ha mostrado que la categoría ontológica de individuo es inadecuada para abordar el dominio de la macroquímica, para el cual resulta más apropiada la categoría de stuff (Lewowicz \& Lombardi, 2013). Asimismo, para el ámbito de la nanoquímica se ha propuesto la categoría de "nanoindividuos", ítems que no son ni individuos (en el sentido anteriormente indicado) ni stuff (Córdoba y Zambón, 2017). Otros autores incluso han propuesto abordajes procesuales y relacionales en química (Kopel, 2019; Needham, 2003; Stein, 2004).

En el contexto de la filosofía actual de la biología, se ha desarrollado recientemente el marco de una ontología procesual, según el cual las macromoléculas biológicas, las células, los órganos, los organismos y las poblaciones son mejor comprendidos como procesos antes que como individuos sustanciales (Nicholson \& Dupré, 2018; Dupré, 2021). Esta visión considera que un organismo no consiste en una jerarquía de estructuras (como si fuera una máquina), sino en una jerarquía dinámica de procesos, estabilizados y mantenidos dinámicamente a diferentes escalas de tiempo (Dupré \& Nicholson, 2018). El mundo viviente, de este modo, no está poblado de individuos sustanciales, ("cosas", en palabras de Dupré y Nicholson). Esta postura no necesariamente implica negar que existan las "cosas"; no obstante, la condición mínima para que una ontología sea considerada como procesual es la de afirmar que los procesos son más fundamentales que las cosas. Esto es, la existencia de las "cosas" es condicional a la existencia de procesos (Dupré \& Nicholson, 2018).

Entonces ¿qué serían las "cosas", los objetos individuales, para la ontología procesual? Acorde a este marco filosófico, las entidades individuales deben ser vistas como abstracciones de procesos estables; son "precipitados" de procesos, en tanto 
que se derivan de ellos. Por tal motivo, no pueden ser consideradas como los bloques fundamentales de la realidad, dado que lo que identificamos como "cosas" no son más que patrones transitorios de estabilidad dinámica inmersa en un flujo circundante. Lo que es fundamental es el cambio, el dinamismo, que es continuo y extendido en el tiempo. De este modo, para la ontología procesual, el mundo viviente consiste en una gran variedad de procesos interrelacionados que colectivamente constituyen un continuo dinámico.

Para la visión procesual, las entidades que parecen actuar como sujetos de las actividades o procesos pueden ser pensadas como estadios temporales específicos de procesos estables. La estabilización de un proceso biológico es dinámica y varía en una escala temporal; por ejemplo, una molécula de ARN mensajero dura minutos, un glóbulo rojo dura meses, un ser humano décadas, etcétera. Estas estabilizaciones temporales pueden provocar la apariencia de que son entidades individuales fijas y estáticas, pero ello ocurre porque son lo suficientemente estables en relación con la escala temporal de otros procesos que ocurren simultáneamente. Por ejemplo, las enzimas pueden ser tratadas como "cosas" porque son estables en la escala temporal de la catálisis (este aspecto será abordado con mayor detalle en la Sección 3).

Los procesos se caracterizan por tener extensión en el tiempo; tienen partes temporales. Mientras que para la ontología de las "cosas", el cambio constituye una suerte de amenaza para la identidad (en tanto que lo esencial es aquello que permanece en el individuo a pesar de los cambios), para la ontología procesual el cambio es un aspecto central, dado que los procesos dependen del mismo para su existencia. Aun así, los procesos pueden presentar fronteras o ser delimitados; es decir, es posible distinguir procesos individuales, así como también es posible determinar una ubicación espacio temporal de un proceso. Pero la individualización de los procesos, a diferencia de la de las "cosas", no se determina respecto de su ubicación espacio-temporal, sino por lo que "hacen". Un proceso individual consiste en actividades causalmente interconectadas o que ocurren juntas en un modo coordinado para un determinado objetivo.

La organización espacio temporal de un proceso y sus relaciones con otros procesos determinan su persistencia y estabilidad, y es lo que también sustenta sus propiedades y poderes causales. En efecto, es posible interrogarse acerca de qué es lo que persiste en el tiempo en los procesos, de modo tal que estos puedan ser distinguidos. Para la ontología procesual, lo que persiste es la forma del estado dinámico, porque la constitución material está constantemente siendo renovada por eventos metabólicos - por ejemplo, las proteínas del cuerpo humano se renuevan en el periodo aproximado de un año y, sin embargo, una célula persiste más allá del recambio de sus materiales.

Los procesos, a su vez, son entidades relacionales, no tienen existencia independiente, porque tanto influencian a su entorno como también se encuentran bajo la influencia del mismo. En este sentido, los procesos son complejos interconectados que se comportan de determinado modo debido a sus relaciones con otras entidades 
en los alrededores (que no son otras cosas que otros procesos circundantes), por lo tanto, el entorno es parte de lo que determina el comportamiento de estas entidades. Es decir, las relaciones, tanto internas como externas, tienen un rol constitutivo.

El abordaje procesual resulta fructífero para abordar el estudio de organismos y otros procesos biológicos en escala macroscópica y microscópica, como el metabolismo celular y otros procesos bioquímicos celulares. Sin embargo, cuando se pone el foco en las macromoléculas biológicas, debe destacarse que estas no son en sí mismas organismos vivientes sino que son consideradas como los "bloques materiales" fundamentales que constituyen a los organismos, y también como los "sujetos" del cambio que ocurre en los procesos bioquímicos. En las secciones siguientes analizaré si es posible extender la concepción procesual a las macromoléculas biológicas. No obstante, para poder abordar ese desafío, resulta necesario previamente indagar cuál es la categoría ontológica que subyace a la concepción actualmente prevaleciente de estas entidades.

\section{Las entidades bioquímicas como individuos que forman clases naturales}

El campo de la bioquímica comprende un ámbito de investigación altamente interdisciplinario. No obstante, es posible diferenciar aquellas cuestiones fundamentales que conforman su objeto de estudio. Estas comprenden, entre otras, identificar las macromoléculas biológicas y elucidar sus estructuras y propiedades, así como también determinar cómo actúan en las funciones biológicas en las que participan y cómo son sintetizadas en los organismos (Voet \& Voet, 2005).

En el caso de las proteínas, un aspecto fundamental a estudiar es la relación entre la secuencia de aminoácidos (la estructura primaria), la estructura macromolecular tridimensional y la función biológica de la proteína. ${ }^{1}$ El comúnmente denominado paradigma SSF (sequence-structure-function, en inglés) consiste básicamente en la concepción de que la secuencia de aminoácidos que forman la estructura primaria de la proteína (también denominada microestructura) determina su plegamiento y, por consiguiente, su estructura tridimensional macromolecular resultante. Esta última, a su vez, explica la función biológica que esa proteína desempeña en el organismo viviente, dado que el plegamiento de la proteína deja expuestas determinadas regiones de su estructura que funcionan como superficies disponibles o susceptibles de interaccionar con otros componentes celulares (usualmente, otras proteínas). Las interacciones que tienen las proteínas principalmente con otras proteínas es la base sobre la cual se clasifican las diferentes funciones y propiedades que estas macromoléculas tienen en

1 Las proteínas sintetizadas en la célula sufren un proceso de plegamiento espontáneo (autoensamblaje) para adquirir las conformaciones denominadas nativas, que son las ocurrentes naturalmente en la célula viva (Voet \& Voet, 2005). 
el complejo entramado celular (Guttinger, 2021). El paradigma SSF ha dominado los estudios de proteínas durante la mayor parte del siglo XX.

Si bien la bioquímica tiene como objeto de estudio los diferentes procesos bioquímicos que ocurren en los organismos, se considera que las entidades fundamentales de este dominio, aquellas que subyacen a los procesos bioquímicos, son las macromoléculas. Estas pueden ser subsumidas en la categoría ontológica de individuos sustanciales, descrita en la Sección 1. En tanto que individuos, las macromoléculas pueden ser agrupadas en clases naturales.

Una de las cuestiones recientemente abordadas en la filosofía de las ciencias particulares ha sido elucidar el tipo de clases que forman las macromoléculas, por ser entidades de interés tanto para la filosofía de la química como para la filosofía de la biología. Las macromoléculas son simultáneamente consideradas entidades químicas en su aspecto estructural y entidades biológicas en su aspecto funcional (Tahko, 2020). Si, por un lado, se considera que las macromoléculas son clases químicas, sus propiedades se explicarían típicamente en términos de la estructura química. Esta es la tesis denominada microestructuralismo, ${ }^{2}$ que considera a la microestructura como la característica distintiva de una clase química y, por lo tanto, también de la clasificación de las entidades. Si, por el otro lado, se considera que el aspecto más relevante de las macromoléculas es el rol que cumplen en los procesos fisiológicos, podríamos hablar de clases funcionales, utilizando la función biológica como criterio clasificatorio (función que se considera como el resultado del proceso evolutivo) (Tahko, 2020).

En relación con la clasificación de las macromoléculas, Jordan Bartol (2016) también diferencia entre clases químicas y clases biológicas, argumentando que mientras que las primeras son generalmente tratadas como compuestas por entidades que tienen identidades fijas y atemporales, las segundas se consideran compuestas por entidades cambiantes en el tiempo (y sujetas al proceso de evolución). A partir de esa distinción, sostiene que las entidades bioquímicas, las macromoléculas, constituyen clases químicas, algunas de las cuales también son clases biológicas, en particular, aquellas evolutivamente conservadas.

Por su parte, Emma Tobin (2010) considera que, si bien el microestructuralismo podría ser extendido, al menos en principio, al caso de las macromoléculas biológicas, no obstante, aun diferentes versiones del microestructuralismo (que la autora distingue) no permiten dar cuenta, en su conjunto, de todos los tipos de clases bioquímicas (es decir, de las propiedades de todas las macromoléculas biológicas). Su razonamiento se basa en el análisis de dos casos particulares, las proteínas medianoche (moonlight

2 Efectivamente, en filosofía de la química, la cuestión de las clases naturales aparece estrechamente vinculada con el análisis del problema del microestructuralismo esencialista, de acuerdo con el cual los elementos y las sustancias químicas se individualizan exclusivamente por su microestructura (cf. Hendry, 2008). Ahora bien, no debe soslayarse que sobre esta posición se ha generado un interesante debate filosófico, a raíz de la consideración de problemas provenientes de la química (cf. Martínez González \& Córdoba, 2016). 
proteins) y las proteínas intrínsecamente desordenadas, como ejemplos en los cuales la estructura primaria de una proteína no permite dar cuenta de las propiedades funcionales.

Las proteínas medianoche reciben este nombre en analogía a la expresión inglesa moonlight job que refiere a los segundos empleos nocturnos que algunas personas tienen en relación con la ocupación principal diurna. Estas proteínas se caracterizan por realizar varias funciones autónomas (a menudo, no relacionadas entre sí), sin que estas funciones se asocien a diferentes dominios estructurales. Un ejemplo son las enzimas, que además de su función catalítica están involucradas en otros procesos no relacionados como la autofagia, el transporte de proteínas o el mantenimiento del ADN (cf. Huberts \& van der Klei, 2010). Algunas proteínas medianoche pueden realizar dos funciones simultáneamente, pero en otros casos, la función biológica cambia en respuesta a los cambios en el entorno (por ejemplo, pueden tener una función en el citoplasma y otra diferente en la membrana celular) (cf. Jeffery, 2014).

Por otro lado, las proteínas intrínsecamente desordenadas (intrinsically disordered proteins o IDP) son macromoléculas que contienen en su estructura primaria regiones no estructuradas de al menos 50 residuos de longitud. Estas regiones desordenadas o no estructuradas se caracterizan por una composición diferente en su secuencia de aminoácidos, ya que contienen una proporción significativamente mayor de aminoácidos pequeños e hidrófilos y residuos de prolina que las regiones estructuradas (Dyson \& Wright, 2005). La característica particular de este grupo de proteínas es que incluso si no están estructuradas, aun así son unidades funcionales y se comportan como proteínas normalmente estructuradas. Las proteínas no estructuradas son inherentemente flexibles y tanto sus estructuras locales como globales pueden ser moldeadas fácilmente por su entorno. Tal plasticidad intrínseca podría potencialmente permitir que una sola proteína reconociera una gran cantidad de dianas biológicas, sin por ello sacrificar la especificidad (Wright \& Dyson, 1999).

Retomando el debate sobre la clasificación de entidades bioquímicas, estos casos muestran cómo una misma microestructura puede resultar en distintas clases bioquímicas, fenómeno al que Tobin se refiere como una "promiscuidad funcional" (Tobin, 2010). Matthew Slater (2009) también rechaza la clasificación de las proteínas que toma como único criterio la estructura macromolecular, aludiendo a que si bien las proteínas son más plausiblemente individuadas por su función biológica, no habría razón para considerar que existe un único criterio para dar cuenta de sus propiedades. De este modo, adhiere a una visión pluralista anti-reduccionista respecto de la clasificación de estas macromoléculas.

En contraposición, William Goodwin (2011) critica el rechazo de la clasificación de proteínas con base en su estructura. El autor pone en consideración las técnicas de laboratorio que se emplean en el estudio bioquímico de las proteínas y argumenta que la estructura primaria debe ser considerada como la característica fundamental que 
permite distinguir las diferentes clases de proteínas, debido a la centralidad explicativa y metodológica que tiene en este campo de estudios.

En la misma línea de pensamiento, Tuomas Tahko (2020) argumenta que hay buenas razones para adoptar un reduccionismo pragmático acerca de las clases bioquímicas, lo que brinda apoyo a una concepción monista de las clases naturales. Como se ha señalado, en el caso de las proteínas medianoche o las proteínas IDP, la estructura no permite dar cuenta de forma completa de las propiedades macroscópicas. Estas proteínas actúan en roles múltiples, siendo un caso de realizabilidad múltiple, ${ }^{3}$ lo cual desafía una reducción uno-a-uno. ${ }^{4}$ Pero de acuerdo con Tahko, las capacidades funcionales diversas de una proteína, en tanto son disposiciones no actualizadas que solo se manifiestan en el entorno apropiado, no representaría un problema irreconciliable para el reduccionismo (cf. Goodwin, 2011; Havstad, 2018). El reduccionismo que Tahko defiende es una tesis débil, ${ }^{5}$ del tipo defendido por John Dupré cuando afirma: "las disposiciones del todo son determinadas por las propiedades de los constituyentes junto con las condiciones circundantes apropiadas" (Dupré, 2012, p. 131), o un reduccionismo incluso más débil, de acuerdo con el cual lo biológico superviene a partir de lo químico y lo físico (cf. el reduccionismo composicional de Gillett, 2007).

De todos modos, el objetivo del presente trabajo no es hacer una crítica del microestructuralismo en bioquímica sino una crítica al "paradigma de la sustancia" que subyace a dicho microestructuralismo. ¿Por qué es posible afirmar que las entidades bioquímicas son actualmente comprendidas como individuos sustanciales? La perspectiva microestructuralista sobre las proteínas está comprometida con una forma potencial de micro-determinismo, en la cual la macroestructura y la función de las proteínas se sustentan en términos de las propiedades intrínsecas y potencialidades de los componentes de la estructura primaria, como si fueran entidades esencialmente inmutables (Santos, Vallejos \& Vecchi, 2020). Según el paradigma SSF, se considera que no hay factores más allá de la microestructura que presenten algún rol relevante en el micro-nivel, en la secuencia de aminoácidos que conforman la cadena polipeptídica. Esta secuencia es considerada una característica intrínseca de una proteína e independiente de la interacción con el contexto, es decir, de las relaciones que las proteínas puedan tener con otras entidades celulares (Guttinger, 2021). En este sentido, las proteínas son concebidas como individuos sustanciales bien definidos - de acuerdo con las características descritas en la

3 El término "realizabilidad" debe ser considerado un término "paraguas", que agrupa una cantidad variada de relaciones de dependencia diferentes, entre las que se incluye la reducción ontológica (cf. Gillett, 2010).

4 La expresión "reducción uno-a-uno" o "reducción ontológica" denomina la idea de que la función biológica se considera idéntica a la microestructura, por lo tanto la primera es comprendida en términos de una reducción basada en la identidad (Tahko, 2020). El rechazo a este tipo de reduccionismo ya ha sido sostenido desde la filosofía de la química, por considerarse que no existe tal relacion "uno-a-uno" entre una sustancia química y una especie cuasi-molecular (cf. Schummer, 1998).

5 Resulta interesante señalar que la posición de Tahko se erige sobre la base de consideraciones pragmáticas y no ontológicas; así lo afirma expresamente el autor. 
Sección 1-, para cuya identidad las relaciones no son fundamentales (las últimas son, incluso, una consecuencia de la cadena de aminoácidos).

Como indica Stephan Guttinger (2021), el caso de las proteínas IDP, a pesar de que su descubrimiento significó, en principio, un cuestionamiento al paradigma SSF, no obstante no alcanzó para promover una completa renovación de la visión de las proteínas como entidades relacionales y dinámicas. El paradigma SSF terminó absorbiendo el caso de las IDP sin fisuras, dado que en esta área de investigación, aún se sigue hablando de la microestructura como un aspecto intrínseco y fundamental de las proteínas (incluyendo a las IDP). Las proteínas no han dejado de ser concebidas como sustancias para los científicos, aun sabiendo de la existencia de esos casos.

Habiendo abordado en esta sección cuál es la categoría ontológica que actualmente prevalece respecto de las macromoléculas (específicamente, las proteínas), en la siguiente sección evaluaré si las entidades bioquímicas pueden ser mejor comprendidas si se las conciben como procesos en lugar de como individuos sustanciales.

\section{3. ¿Es posible una visión procesual de las entidades bioquímicas?}

Como fue abordado en la Sección 1, en el marco de una ontología de la sustancia, las entidades son distinguibles entre sí y pueden o no interaccionar entre ellas, pero lo que hace a su comportamiento está unívocamente vinculado a su estructura interna y no a sus relaciones con el entorno (consideradas externas). En contraste con ello, los aspectos relacionales, dinámicos y temporales son centrales en una ontología procesual, que se posiciona como fundamentalmente crítica de las posturas esencialistas y reduccionistas (cf. Dupré \& Nicholson, 2018). Sin embargo, el rechazo al microestructuralismo no es condición suficiente para sostener una ontología procesual, dado que se puede criticar esa posición desde otras ontologías relacionales pero no necesariamente procesuales (ver Santos, Vallejos \& Vecchi, 2020). ${ }^{6}$

Siguiendo a Seibt (2021), dentro de las tareas más importantes de una filosofía procesual se encuentra poder dar cuenta de lo mismo que con la otra ontología. Veremos a continuación cómo se puede comprender la naturaleza de las macromoléculas biológicas bajo un enfoque procesual.

Ross Stein $(2004 ;$ 2006) propone un marco ontológico procesual en química y bioquímica, tomando como punto de partida la aplicación de un modelo ecológico para las moléculas (Cobb, 1988). Este modelo ecológico consiste en la idea de que

6 Gil Santos, Gabriel Vallejos y Davide Vecchi (2020) también rechazan el reduccionismo ontológico de la función biológica hacia la secuencia de aminoácidos tal como propone el microestructuralismo, señalando que resulta necesario dar cuenta del rol causal top-down que existe en el fenómeno de plegamiento a partir de considerar las relaciones entre la macromolécula y su entorno). Por tal motivo, los autores defienden un abordaje relacional de las proteínas, en el cual resultan clave el interjuego dinámico entre el micro-nivel de las partes y el macro-nivel de las estructuras relacionales de sus sistemas. 
los átomos adquieren diferentes propiedades cuando se organizan en diferentes estructuras moleculares, porque estas constituyen entornos diferentes. De modo que las propiedades de los átomos están determinadas por las relaciones con su entorno (Cobb, 1988). A partir de esta idea, Stein se basa en los conocimientos actuales sobre la función enzimática y afirma que las enzimas tienen que ser comprendidas como ecosistemas, a los que considera como complejos relacionales e interconectados. La disposición espacial tridimensional de los residuos de aminoácidos del sitio activo de una enzima alrededor del sustrato es claramente un factor de importancia crítica para la química de la enzima, pero así también lo es la matriz de proteínas que se encuentra en continua comunicación dinámica con estos residuos, lo cual le confiere a la enzima el estado de funcionar como un catalizador enzimático. Esta dinámica del sitio activo de una enzima se acopla, en última instancia, al disolvente circundante (el agua). Esto conduce, según Stein (2014), a una nueva comprensión de los orígenes de la capacidad catalítica de una enzima: la proteína "paga" el costo energético de la catálisis transmitiendo la energía que está disponible de sus interacciones estocásticas con el medio hacia el sitio activo.

Siguiendo esta concepción ecológica, Guttinger (2018) afirma que las macromoléculas son entidades relacionales que conforman un sistema. De forma análoga a la simbiosis que ocurre en una colonia de termitas, el comportamiento del sistema está definido por unas capacidades integradas que emergen del todo integrado. La capacidad catalítica de una enzima no es simplemente la capacidad de la estructura de la enzima, como si estuviera predeterminada de forma rígida previamente a su encuentro con el sustrato. Su poder catalítico se basa en una capacidad integrada que es habilitada por las relaciones dinámicas con su entorno. De modo que las entidades y la actividad no pueden ser separadas en el sentido que se las concebiría bajo una perspectiva mecanicista basada en una dualidad de individuos sustanciales que "realizan" actividades (Dupré, 2021).

En un trabajo reciente, Guttinger (2021) argumenta que la forma en la que se estudian las proteínas hace aparentar que son entidades individuales estáticas debido al uso de determinadas prácticas de investigación experimental destinadas al manejo de los niveles de energía involucrados en el sistema de estudio. Ahora bien, el autor observa que desde el punto de vista químico, la estructura primaria consiste en unidades de aminoácidos unidos por enlaces peptídicos. Estos aminoácidos, a su vez, son susceptibles de "protonarse" (capturar hidrogeniones) o "desprotonarse" (liberar hidrogeniones), acorde al pH del medio circundante. El número de protones presente en una proteína se conoce como el "estado de protonación"; cualquier variación en el pH significa un cambio en el estado de protonación de esa proteína, y por consiguiente, de la carga eléctrica neta de la misma, lo cual implica que aquellas propiedades que estén influenciadas por la carga eléctrica se verán modificadas. Es en este sentido, según Guttinger, que la microestructura de una proteína puede cambiar debido al estado de protonación, aun cuando la cadena de aminoácidos sea la misma. 
En efecto, para conocer la microestructura es necesario conocer los parámetros del sistema en el cual esa proteína se encuentra, de modo que las relaciones también afectan el nivel microestructural. De hecho, concebir a las microestructuras como aparentemente estables o fijas es, en verdad, la consecuencia de aplicar determinadas prácticas que permiten manejar los niveles de energía del sistema experimental (como por ejemplo, el enfriamiento o la utilización de medios tamponados o buffers para mantener estabilizado artificialmente el pH en el tubo de ensayos). De este modo, el autor muestra como "la estabilidad es producida y mantenida" (Guttinger, 2021, p. 49) a partir de dichas prácticas experimentales, tras lo cual, la naturaleza relacional y dinámica de estas macromoléculas se invisibiliza, permitiendo considerarlas como entidades perfectamente delimitadas e independientes del entorno.

Un problema importante de abordar desde una perspectiva procesual es cómo dar cuenta del cambio bioquímico a partir de entidades estáticas, como "aparentemente" lo son las sustancias bioquímicas. En este sentido, es relevante retomar las consideraciones de Joachim Schummer (1998) en el ámbito de la filosofía de la química. Schummer sostiene que, pese a que la identidad de las sustancias químicas tiene aspectos relacionales imposibles de soslayar, no obstante resulta necesario apelar al concepto de sustancias químicas (como aquello que no varía frente al cambio) para dar cuenta de la red conceptual de la química, esto es, para identificar que hubo un cambio: que una sustancia dejó de ser la que era y pasó a ser otra en una reacción química.

Ahora bien, desde un marco ontológico procesual, dado que el cambio es la norma, entonces es la estabilidad lo que debe ser explicado. Bajo su concepción de las moléculas como ecosistemas, Stein (2004) propone que en una reacción, el cambio químico puede ser pensado como un cambio en los patrones de estabilidad. De forma similar a un ecosistema, la molécula perdura en el tiempo y mantiene su identidad no porque sea estática e inmutable, sino porque es un sistema dinámico que exhibe un patrón de estabilidad a través del tiempo. Visto de esta manera, el cambio químico representa un pasaje hacia un nuevo patrón de estabilidad duradera, es decir, una progresión de un estado dinámico a otro.

A partir de esta concepción del cambio químico, entonces, ¿cómo se alcanza esa estabilidad? La "aparente" estabilidad que se les confiere a las sustancias químicas no sería más que una estabilidad "artificial" propiciada por las condiciones experimentales de obtención o de purificación de dicha sustancia. Esa estabilidad es alcanzada relacionalmente. De acuerdo con Schummer (1998), una sustancia química pura es el "output" de nuestros métodos de purificación. Si cambiamos las condiciones, obtendremos otro "output", de modo que las sustancias puras, según el autor, están definidas inevitablemente de forma operacional.

En el caso de las macromoléculas biológicas, las condiciones que les confieren estabilidad son las de su contexto natural de ocurrencia (la célula, un tejido, un 
organismo, etcétera). Ese contexto puede ser visto como un complejo dinámico en el que el inventario de objetos es en sí mismo un objetivo que el sistema trabaja constantemente para estabilizar o adaptarse a condiciones variables (Dupré, 2021). El concepto de red de proteostasis permite visualizar este aspecto de forma más clara. El conjunto de proteínas de una célula, el proteoma, es mantenido y depende de una extensa red de chaperonas moleculares, sistemas proteolíticos y sus reguladores. La red de proteostasis sirve para asegurar que las proteínas no solo se plieguen correctamente sino también se generen en el momento, con la ubicación y la cantidad adecuada, de modo que permitan su ensamblaje con otras sustancias. Juntos, estos mecanismos evitan la acumulación de agregados de proteínas, que podrían ser potencialmente tóxicos (cf. Hipp, Kasturi \& Hartl, 2019).

Tras estas consideraciones sobre las macromoléculas biológicas como entidades procesuales estabilizadas relacionalmente, en la siguiente sección presentaré el caso de los receptores celulares y los fenómenos de bioseñalización celular, con el fin de argumentar que la perspectiva procesual también resulta adecuada en este caso.

\section{El caso de los receptores bioquímicos y la señalización celular desde la perspectiva procesual}

Los seres vivos coordinan sus actividades en todo nivel de su organización por medio de sofisticados sistemas de señales químicas, denominados sistemas de señalización biológica o bioseñalización (ver Avendaño, 2001; Curtis, Barnes, Schnek, \& Massarini, 2013; Silverman, 2004; Voet \& Voet, 2005; entre otros). Los receptores celulares son macromoléculas de naturaleza proteica que se encuentran en las células (en la membrana celular o en el interior citoplasmático), y su función consiste en mediar o transmitir la señal de mensajeros químicos provenientes del exterior celular (por ejemplo, una hormona o un fármaco), lo cual desencadena una repuesta biológica.

El concepto de receptor es uno de los pilares de la bioquímica, fisiología y farmacología actual. La postulación de la existencia de receptores celulares permite brindar una explicación satisfactoria para los procesos de señalización biológica y los mecanismos de acción de muchas sustancias de acción específica. Las señales son moléculas, generalmente de baja masa molecular, que interactúan con los receptores de forma específica, dando lugar a la formación de un complejo en el que la molécula señal se denomina ligando. En el caso de los receptores ubicados en la membrana celular, cuando la señal alcanza su sitio diana u objetivo, se forma un complejo ligando-receptor $(\mathrm{L}-\mathrm{R})$, que existe por un período de tiempo muy corto y que transmite el mensaje hacia el interior celular.

La unión L-R es mediada por enlaces químicos de diferente fuerza y estabilidad entre la estructura química del ligando y la del receptor, de modo que la interacción 
entre ambos es altamente específica (y reversible en la mayoría de los casos). Los primeros modelos de la interacción L-R hacían una analogía con una llave-cerradura, para indicar que entre el receptor (o la enzima) y el ligando (o el sustrato) existía una complementariedad estructural rígida que les permitía interactuar tan específicamente. Este modelo tiene su origen en la teoría propuesta por Emil Fischer en 1894 para explicar el comportamiento de una enzima y su sustrato específico. A partir de la segunda mitad del siglo XX, la interacción L-R ha cambiado, y se han puesto de relieve los aspectos dinámicos de esta interacción. Uno de los primeros modelos en capturar estos conocimientos fue el modelo del ajuste inducido de Daniel Koshland (publicado por primera vez en 1958).

Existen dos clases de moléculas químicamente semejantes a los ligandos: los agonistas, que reproducen la función del ligando uniéndose a su receptor y causando la respuesta normal, y los antagonistas, que se unen al receptor pero no reproducen la función del ligando y actúan como un inhibidor al competir por el mismo sitio de unión.

Hay dos conceptos que son fundamentales para explicar la interacción L-R. Uno de ellos es el de afinidad, definida como la capacidad que posee un ligando de unirse a un receptor específico y formar un complejo L-R. El otro es la actividad intrínseca, entendida como la capacidad que tiene un ligando unido al receptor de activar y desencadenar una acción biológica. Los ligandos agonistas son aquellos que tienen gran afinidad y elevada actividad intrínseca, mientras que los ligandos antagonistas tienen gran afinidad pero carecen de actividad intrínseca. Los denominados agonistas parciales son aquellos que tienen elevada afinidad pero actividad intrínseca limitada o intermedia.

Existen diversos tipos de receptores acoplados a diferentes mecanismos, lo cual permite comprender cómo actúan una enorme cantidad de señales. Muchas enfermedades están actualmente vinculadas con algún sistema de transducción de señales, como por ejemplo: la acción de diversas toxinas (cólera, toxinas paralizantes, venenos de serpientes), la formación de tumores y cáncer, el desarrollo de diabetes, y diversos trastornos neurológicos. Más del 60\% de los fármacos aprobados en la actualidad se conoce que ejercen sus efectos terapéuticos al interactuar con un receptor o bien alguna estructura relacionada con un receptor (Santos et al, 2017; voet \& Voet, 2005).

En una revisión reciente, Wang, Bugge, Kragelund \& Lindorff-Larsen (2018) ponen de relieve la importancia de los aspectos dinámicos en el estudio de los receptores transmembrana. Los autores revisan varios ejemplos de diferentes clases de receptores para mostrar que los cambios en la conformación tridimensional de estas macromoléculas, tanto en diferentes escalas de tiempo así como también escalas de longitud, resultan fundamentales para comprender su función biológica. Los receptores celulares funcionan en un entorno heterogéneo y cambian entre distintos estados funcionales; por este motivo, los investigadores afirman que pueden ser 
particularmente sensibles a pequeñas perturbaciones externas y que, en efecto, la dinámica estructural juega un rol clave para su activación (Wang et al, 2018).

Incluso para uno de los tipos de receptores más ampliamente estudiados, los receptores acoplados a proteína G (GPCR, en inglés), aún queda mucho por descubrir acerca del rol de la dinámica estructural en la función biológica. Al respecto, Manglik y Kobilka (2014) señalan que aunque las estructuras dilucidadas por cristalografía de Rayos-X de los GPCR sugieren un mecanismo de activación del receptor de tipo on-off que varía entre dos estados (uno activo y otro inactivo), otros estudios biofísicos y la amplia variedad que se observa en el fenómeno de bioseñalización sugieren que los GPCR son altamente dinámicos y existen en una multitud de conformaciones funcionalmente distintas.

Las funciones celulares son usualmente representadas mediante los diferentes mecanismos moleculares que conforman las rutas metabólicas celulares, usualmente descritos en términos de interacciones específicas entre proteínas. Un aspecto importante del fenómeno de bioseñalización celular o del mecanismo de acción específico de una droga, es la elucidación de la secuencia de eventos que ocurren en el nivel molecular hacia el interior de la célula, como consecuencia de la activación del complejo L-R, en los cuales las interacciones entre las proteínas intracelulares con otros componentes (por ejemplo, otras proteínas) son fundamentales. Para que un organismo funcione correctamente, el sistema debe tener una estabilidad frente a tal asociación entre proteínas, de modo que tal que las proteínas no se "abarroten" entre sí y puedan seguir interaccionando con otros componentes celulares.

En este sentido, las interacciones atractivas dipolo-dipolo (enlace de hidrógeno) y/o ion-dipolo deben ser en algún punto superadas por las repulsivas, en modo tal que los encuentros entre proteínas tampoco sean eventos raros o poco probables. En este delicado equilibrio funcional de las células, Wennerström, Estrada, Danielsson \& Oliveberg (2020) han evidenciado que la composición única de poli-iones de los sistemas celulares hace que las interacciones electrostáticas intermoleculares en estos sean diferentes a aquellas manifiestas en condiciones estandarizadas para estudiarlas in vitro, existiendo una mayor sensibilidad in vivo de las proteínas a la interacción electrostática con otros pequeños iones de lo que usualmente se consideraba.

Asimismo, recientemente se han desarrollado nuevas técnicas capaces de monitorear diferentes proteínas en el contexto natural de una célula viva, con el fin de poner de relieve la importancia del entorno de solvatación celular, a menudo desatendido en el estudio de las funciones de las proteínas. Un consenso emergente es que los procesos de las proteínas en la célula se ven afectados, además, por una combinación de interacciones estéricas y no estéricas en el medio solvatado (o acuoso). Davis, Gruebele y Sukenik (2018) explican cómo el área de superficie de las proteínas y los cambios de volumen molecular controlan estos tipos de interacciones y brindan ejemplos 
recientes que resaltan cómo incluso cambios ambientales leves pueden alterar los procesos celulares. Cabe mencionar que igualmente en el contexto de la membrana celular, ubicación natural de los receptores transmembrana, la variación espacial y temporal en la composición de lípidos afecta las propiedades generales de la bicapa y también puede desempeñar funciones específicas en la estabilización de proteínas transmembrana así como también en la regulación de su función biológica (cf. Grouleff, Irudayam, Skeby \& Schiøtt, 2015).

Otros avances recientes permiten poner en cuestión la concepción de los receptores como entidades pre-determinadas, aspecto que es capturado por la conocida analogía de la llave-cerradura. Para el caso de los receptores que contienen regiones desordenadas en su estructura (es decir, que son proteínas IDP), el plegamiento de la región desordenada que ocurre tras la unión al ligando es considerado en sí mismo un modo importante de reconocimiento molecular (Yang, Gao, Xiong, Su \& Huang, 2019). En estos casos, no sería posible hablar de un receptor "pre-determinado", como lo es una cerradura para su llave.

Por otro lado, los conceptos de actividad constitutiva y de selectividad funcional en la farmacología contemporánea también permiten arrojar dudas sobre la visión clásica de los receptores como representados en la analogía llave-cerradura. Observan Kelly Berg y William Clarke (2018) que si bien la teoría tradicional de receptores postula que los mismos están inactivos a menos que sean activados por un ligando, no obstante, existe evidencia de que los receptores pueden estar activos sin un ligando activador (agonista), y, por lo tanto, pueden mostrar una actividad constitutiva. La magnitud de esta actividad depende de aspectos dinámicos - por ejemplo, la flexibilidad conformacional de la estructura de la proteína (que permita una rápida y fácil isomerización desde el estado inactivo hacia el estado activo) - y contexto-dependientes - por ejemplo, el hecho de que esta actividad constitutiva se vea favorecida en aquellas células donde hay mayor densidad de receptores "constitutivamente" activos (Berg \& Clarke, 2018).

Los autores también señalan el caso de la selectividad funcional de los fármacos, para referirse a los casos en que dos fármacos que actúan como agonistas para un mismo subtipo de receptor pueden tener diferentes eficacias intrínsecas para las respuestas intracelulares acopladas a dicho receptor (Berg \& Clarke, 2018). En efecto, no basta con conocer la eficacia intrínseca de un fármaco respecto de un subtipo de receptor (es decir, la capacidad de activarlo), sino que es necesario estudiar cuáles de todas las vías de señalización intracelulares acopladas al receptor, activa en particular ese fármaco. Aquí se observa, entonces, que no hay tal pre-determinación, como era sugerida por la analogía llave-cerradura.

A partir de lo repasado en esta sección, podemos considerar que la bioseñalización celular es un proceso complejo. En el estudio de este fenómeno, tradicionalmente se ha considerado que los receptores son los sujetos de ese proceso (en tanto que 
"mediadores" de la señalización celular), y además, que son entidades pre-determinadas cuya naturaleza no depende, en un sentido fundamental, de las relaciones con el entorno. Sin embargo, los conocimientos actuales mencionados en esta sección motivan a reflexionar que no solo el fenómeno de bioseñalización celular puede concebirse bajo la ontología procesual sino que los receptores mismos, también. Habiendo presentado algunos conceptos básicos del concepto de receptor celular y del fenómeno de bioseñalización, es posible incluso poner en cuestión la idea de que las macromoléculas biológicas sean las unidades fundamentales en bioquímica. Solo tiene sentido hablar de ellas como entidades bioquímicas en el contexto celular, en donde se les atribuyen determinadas propiedades o funciones. Esto solo puede ser captado, sostenido, o conceptualizado desde un marco procesual.

\section{A modo de conclusión}

Este trabajo constituye una primera aproximación en el análisis del caso de los receptores celulares y del fenómeno de señalización celular desde la perspectiva de la ontología procesual. Esta perspectiva prioriza el cambio por sobre la estabilidad, como aspecto fundamental de la realidad. Las consecuencias de adoptar una ontología procesual incluyen, entre otros aspectos, el de considerar que, si el cambio es lo fundamental, entonces de lo que hay que dar cuenta en la naturaleza viviente es de cómo se alcanza la estabilidad mediante el cambio continuado.

Los conocimientos actuales permiten concebir a los receptores como entidades dinámicas, estabilizadas relacionalmente, contexto-dependientes y no predeterminadas. La ontología de los individuos sustanciales no captura todos estos aspectos presentados en las secciones 3 y 4 . Desde una perspectiva procesual, sería posible admitir que los receptores, típicamente considerados como los "sujetos" de la bioseñalización celular, serían, en verdad, "precipitados" de dicho proceso, entidades secundarias al proceso mismo de bioseñalización. El conjunto de proteínas en una célula es un complejo dinámico constituido por transformaciones y estabilizaciones variadas que no pueden reducirse a las actividades de un conjunto de individuos sustanciales, sino que son el resultado de una negociación constante entre las proteínas, los otros tipos de moléculas y macromoléculas, y el medio acuoso (Dupré, 2021).

Finalmente, esta primera aproximación aquí presentada podría seguir profundizándose a la luz de las prácticas empleadas en la investigación bioquímica actual, así como también extenderse hacia el análisis de otras entidades bioquímicas y macromoléculas, como los ácidos nucleicos, carbohidratos y lípidos. En este sentido, la ontología procesual pareciera resultar prometedora y podría aportar en el desarrollo de una filosofía especial de la bioquímica. 


\section{Referencias}

Avendaño, C. (2001). Introducción a la química farmacéutica (2º ed.). Madrid.

Bartol, J. (2016). Biochemical kinds. The British journal for the philosophy of science, 67(2), 531-551. https://doi.org/10.1093/bjps/axu046

Bensaude-Vincent, B. (2014). Philosophy of chemistry or philosophy with chemistry. HYLE: International Journal for Philosophy of Chemistry, 20, 58-76.

Berg, K. A. \& Clarke, W. P. (2018). Making sense of pharmacology: inverse agonism and functional selectivity. International Journal of Neuropsychopharmacology, 21(10), 962-977. https:// doi.org/10.1093/ijnp/pyy071

Cobb, J.B. (1988). Ecology, science, and religion: toward a postmodern worldview. In D.R. Griffin (Ed.), The Reenchantment of Science (99-114). State University of New York Press.

Córdoba, M. y Zambon, A. (2017). How to handle nanomaterials? The re-entry of individuals into the philosophy of chemistry. Foundations of Chemistry, 19(3), 185-196. https://doi. org/10.1007/s10698-017-9283-6

Curtis, H., Barnes, S., Schnek, A. y Massarini, A. (2013). Curtis Biología, Séptima edición. Buenos Aires.

Davis, C. M., Gruebele, M. \& Sukenik, S. (2018). How does solvation in the cell affect protein folding and binding? Current opinion in structural biology, 48, 23-29. https://doi. org/10.1016/j.sbi.2017.09.003

Dupré, J. (2012). Processes of life: essays in the philosophy of biology. Oxford University Press. https://doi.org/10.1093/acprof:0so/9780199691982.001.0001

Dupré, J. (2021). The metaphysics of biology (elements in the philosophy of biology). Cambridge University Press. https://doi.org/10.1017/9781009024297

Dupré, J. \& Nicholson, D. (2018). A manifesto for a processual philosophy of biology. In D. Nicholson \& J. Dupré (Ed.), Everything flows: towards a processual philosophy of biology (pp. 3-45). Oxford University Press.

Dyson, H.J. \& Wright, P.E. (2005). Intrinsically unstructured proteins and their functions. Nature Reviews Molecular Cell Biology, 6, 197-208. https://doi.org/10.1038/nrm1589

French, S. \& Krause, D. (2006). Identity in physics: a historical, philosophical and formal analysis. Oxford University Press.

Gillett, C. (2007). Understanding the new reductionism: the metaphysics of science and compositional reduction. The Journal of Philosophy, 104, 193-216. https://doi. org/10.5840/jphil2007104427

Gillett, C. (2010). Moving beyond the subset model of realization: the problem of qualitative distinctness in the metaphysics of science. Synthese, 177, 165-92. https://doi. org/10.1007/s11229-010-9840-1 
Goodwin, W. (2011). Structure, function, and protein taxonomy. Biology \& Philosophy, 26(4), 533-545. https://doi.org/10.1007/s10539-011-9252-8

Grouleff, J., Irudayam S.J., Skeby, K.K. \& Schiøtt, B. (2015). The influence of cholesterol on membrane protein structure, function, and dynamics studied by molecular dynamics simulations. Biochim Biophys Acta (BBA) - Biomembr. 1848(9), 1783-1795. https://doi. org/10.1016/j.bbamem.2015.03.029

Guttinger, S. (2018). A process ontology for macromolecular biology. In D. Nicholson \& J. Dupré (Ed.), Everything flows: towards a processual philosophy of biology (pp. 303-320). Oxford University Press. https://doi.org/10.1093/oso/9780198779636.003.0015

Guttinger, S. (2021). Process and practice: understanding the nature of molecules. HYLE: International Journal for Philosophy of Chemistry, 27, 47-66. http://www.hyle.org/ journal/issues/27-1/guttinger.htm

Havstad, J. C. (2018). Messy chemical kinds. British Journal for the Philosophy of Science, 69, 719-43. https://doi.org/10.1093/bjps/axw040

Hendry, R. (2008). Microstructuralism: problems and prospects. In J. van Brakel \& K. Ruthenberg (Eds.), Stuff - The nature of chemical substances (pp. 107-121). Würzburg: Königshauen \& Neumann.

Hipp, M. S., Kasturi, P. \& Hartl, F. U. (2019). The proteostasis network and its decline in ageing. Nature reviews Molecular cell biology, 20(7), 421-435. https://doi.org/10.1038/s41580019-0101-y

Huberts, D. H. \& van der Klei, I. J. (2010). Moonlighting proteins: an intriguing mode of multitasking. Biochimica et Biophysica Acta (BBA) - Molecular Cell Research, 1803(4), 520-525. https://doi.org/10.1016/j.bbamcr.2010.01.022

Jeffery, C. (2014). An introduction to protein moonlighting. Biochemical Society Transactions, 42(6), 1679-1683. https://doi.org/10.1042/BST20140226

Kaiser, M.I. \& Trappes, R. (2021). Broadening the problem agenda of biological individuality: individual differences, uniqueness and temporality. Biology \& Philosophy, 36(15). https:// doi.org/10.1007/s10539-021-09791-5

Krause, D. \& Arenhart, J.R.B. (2016). Individuality, quantum physics, and a metaphysics of non-individuals. The role of the formal. In A. Guay \& T. Pradeu (Eds.), Individuals Across the Sciences (pp 61-84). Oxford University Press. https://doi.org/10.1093/acprof:0 so/9780199382514.003.0005

Kopel, J. (2019). A note regarding relational ontology in chemistry. Process Studies, 48(1), 59-66. https://doi.org/10.5840/process20194815

Lewowicz, L. \& Lombardi, O. (2013). Stuff versus individuals. Foundations of Chemistry, 15(1), 65-77. https://doi.org/10.1007/s10698-012-9152-2

Lowe, E.J. (2003). Individuation. In M.J. Loux \& D.W. Zimmerman, (Eds.), The Oxford Handbook of Metaphysics (pp. 75-95). Oxford University Press. 
Lowe, E.J. (2016), Non-individuals. In A. Guay \& T. Pradeu (Eds.), Individuals Across the Sciences (pp 49-60). Oxford University Press. https://doi.org/10.1093/acprof:0 so/9780199382514.003.0004

Martínez González, J. C., y Córdoba, M. (2016). El problema de las clases naturales en química: algunas dificultades para el microestructuralismo. Crítica (México, DF), 48(144), 89-117. https://doi.org/10.22201/iifs.18704905e.2016.214

Manglik, A. \& Kobilka, B. (2014). The role of protein dynamics in GPCR function: insights from the $\beta 2 A R$ and rhodopsin. Current opinion in cell biology, 27, 136-143. https://doi. $\operatorname{org} / 10.1016 / j . c e b .2014 .01 .008$

Needham, P. (2003) Continuants and Processes in Macroscopic Chemistry. In J. Seibt (Eds.), Process Theories (237-265). Springer. https://doi.org/10.1007/978-94-007-1044-3_10

Nicholson, D. y Dupré, J. (Eds.). (2018). Everything flows: towards a processual philosophy of biology. Oxford University Press. https://doi.org/10.1093/oso/9780198779636.001.0001

Ruthenberg, K. \& van Brakel, J. (Eds.). (2008). Stuff. The Nature of Chemical Substances. Königshauen \& Neumann.

Santos, G., Vallejos, G. \& Vecchi, D. (2020). A relational-constructionist account of protein macrostructure and function. Foundations of Chemistry 22, 363-382. https://doi. org/10.1007/s10698-020-09373-5

Seibt, J. (2018). Ontological tools for the process turn in biology some basic notions of general process theory. In D. Nicholson \& J. Dupré (Eds.), Everything flows: towards a processual philosophy of biology (pp. 113-136). Oxford University Press. https://doi.org/10.1093/ oso/9780198779636.003.0006

Seibt, J. (2021). Process Philosophy. In E. N. Zalta (Ed.), The Stanford Encyclopedia of Philosophy (Fall 2021 Edition). https://plato.stanford.edu/archives/fall2021/entries/processphilosophy/.

Schummer, J. (1998). The chemical core of chemistry I: a conceptual approach. HYLE: International Journal for Philosophy of Chemistry, 4, 129-162.

Slater, M. H. (2009). Macromolecular pluralism. Philosophy of Science, 76(5), 851-863. https:// doi.org/10.1086/605817

Silverman, R. B. \& Holladay, M. W. (2004). The organic chemistry of drug design and drug action. Academic press.

Stein, R. L. (2004). Towards a process philosophy of chemistry. HYLE: International Journal for Philosophy of Chemistry, 10(4), 5-22.

Stein, R. L. (2006). A process theory of enzyme catalytic power - the interplay of science and metaphysics. Foundations of Chemistry, 8, 3-29. https://doi.org/10.1007/s10698005-7907-8

Tahko, T. E. (2020). Where do you get your protein? Or: biochemical realization. The British journal for the philosophy of science, 71(3), 799-825. https://doi.org/10.1093/bjps/axy044 
Tobin, E. (2010). Microstructuralism and macromolecules: the case of moonlighting proteins. Foundations of Chemistry, 12(1), 41-54. https://doi.org/10.1007/s10698-009-9078-5

Voet, D. \& Voet, J. (2004). Bioquímica. Médica Panamericana.

Wang, Y., Bugge, K., Kragelund, B. B. \& Lindorff-Larsen, K. (2018). Role of protein dynamics in transmembrane receptor signalling. Current opinion in structural biology, 48, 74-82. https://doi.org/10.1016/j.sbi.2017.10.017

Wennerström, H., Estrada, E. V., Danielsson, J. \& Oliveberg, M. (2020). Colloidal stability of the living cell. Proceedings of the National Academy of Sciences, 117(19), 10113-10121. https://doi.org/10.1073/pnas.1914599117

Wright, P. E. \& Dyson, H. J. (1999). Intrinsically unstructured proteins: re-assessing the protein structurefunction paradigm. Journal of Molecular Biology, 293(2), 321-331. https://doi. org/10.1006/jmbi.1999.3110

Yang, J., Gao, M., Xiong, J., Su, Z. \& Huang, Y. (2019). Features of molecular recognition of intrinsically disordered proteins via coupled folding and binding. Protein Science, 28(11), 1952-1965. https://doi.org/10.1002/pro.3718 